\title{
Acumulação por espoliação e uso corporativo do território: a concessão das rodovias federais BR-060 e BR-153 em Goiás (Brasil)
}

\author{
Accumulation by spoliation and use corporate \\ governance of the territory: the granting of highways \\ BR-060 and BR-153 in Goiás (Brazil)
}

\author{
Dallys Dantas ${ }^{1}$ (1) e Denis Castilho² (1)
}

\begin{abstract}
RESUMO
As rodovias federais BR-060 e BR-153 formam importantes eixos de integração econômica do Centro-Oeste brasileiro. Em Goiás, possuem os maiores volumes de tráfego e cortam os municípios mais populosos e com maiores indicadores de produção econômica do estado. É por essa importância territorial e pela crescente circulação que trechos estratégicos dessas rodovias entraram em processo de concessão, assinado em janeiro de 2014 entre a Agência Nacional de Transporte Terrestre (ANTT) e a Triunfo Concessionária das Rodovias Centrais do Brasil (Concebra). Este estudo analisa a importância logística dessas rodovias e as implicações territoriais advindas da concessão. O modo como o Estado entrega importantes infraestruturas como essas, melhorando e duplicando trechos antes de serem concedidos, além de oferecer custos baixos e condições financeiras para a apropriação privada, evidencia um ostensivo processo espoliativo-acumulativo e o adensamento do uso corporativo do território acompanhado pela seletividade da fluidez e por uma lógica de circulação extrovertida.
\end{abstract}

Palavras-chave: Concessão rodoviária, Goiás, espoliação, uso corporativo do território.

\section{ABSTRACT}

The BR-060 and BR-153 federal highways compose important axis of economic integration of the Brazilian Mid-West. In the state of Goiás, they have the major volumes of traffic and cross the most populous municipalities with the major indexes of economic production of the state. Therefore, because of its territorial importance and by the growing circulation that strategic stretches of these highways got into the process of concession, signed in January of 2014 between Brazilian National Land Transportation Agency (ANTT) and Triunfo Dealership of the Brazilian Mid-West Highways (Concebra). This study analyzes the logistics importance of these highways and the territorial implications coming from the concession. The means which the State delivers important infrastructures like these, improving and doubling stretches before being conceded, beyond offering low costs and financial conditions for the private appropriation, show an ostentatious spoliative-accumulative process and the densification of the corporative use of the territory followed by the selectivity of flows and an outgoing logic of circulation.

Keywords: Highway concession, State of Goiás, spoliation, corporative use of the territory. 


\section{RESUMEN}

Las carreteras federales BR-060 y BR-153 forman importantes ejes de integración económica del Centro-Oeste brasileño. En Goiás, tienen los mayores volúmenes de tráfico y cortan los municipios más poblados y con mayores indicadores de producción económica del estado. Es por esa importancia territorial y por la creciente circulación que trechos estratégicos de esas carreteras entraron en proceso de concesión, firmado en enero de 2014 entre la Agência Nacional de Transporte Terrestre (ANTT) y la Triunfo Concesionaria de las Carreteras Centrales de Brasil (Concebra). Este estudio analiza la importancia logística de esas carreteras y las implicaciones territoriales derivadas de la concesión. El modo como el Estado entrega importantes infraestructuras como éstas, mejorando y duplicando carreteras antes de su concesión, además de ofrecer costos bajos y condiciones financieras para la apropiación privada, evidencia un ostensivo proceso espoliativo-acumulativo y el adensamiento del uso corporativo del territorio acompañado por la selectividad de la fluidez y por una lógica de circulación extrovertida.

Palabras clave: Concesión de carreteras, Goiás, desposesión, uso corporativo del territorio.

As rodovias respondem por $63 \%$ do volume total de transporte no Brasil (CNT, 2017). O arranjo dessas vias, o modo como são planejadas, apropriadas e controladas são reveladores dos usos do território e das implicações que esses usos têm na dinâmica de circulação e dos fluxos. Como diz Harvey (2005a), sem circulação não há acumulação. Se a esfera da circulação não se expande, a acumulação se estaciona.

A concessão de rodovias, por um lado, significa apropriação e controle de uma rede que viabiliza a circulação e que se constitui como condição fundamental do processo de acumulação. Por outro, ela também se revela um grande negócio, especialmente em países como o Brasil, pelo modo como o Estado concede importantes infraestruturas (em muitos casos pavimentando e duplicando trechos antes de serem entregues), viabilizando custos muito baixos, fornecendo condições financeiras atrativas e ainda garantindo, por meio de instrumento jurídico, o equilíbrio econômico financeiro das concessionárias. Isso evidencia um ostensivo processo espoliativo-acumulativo ainda mais perverso que a privatização.

Tendo isso em vista, como ocorreu o processo de concessão de rodovias federais em Goiás? O que justifica a escolha de trechos das rodovias federais BR-060 e BR-153 e quais são suas implicações políticas e territoriais?

Com base nestas questões, este estudo desenvolve uma análise dos trechos de rodovias federais concedidos em Goiás, discorre sobre o sentido político do processo de concessão e suas consequências territoriais com base nos conceitos de acumulação por espoliação (Harvey, 2005b), uso corporativo do território (Santos e Silveira, 2008) e fluidez territorial (Arroyo, 2005 e 2015). Os procedimentos metodológicos basearam-se em levantamento e análise de dados da Agência Nacional de Transportes Terrestres (ANTT), Banco Nacional do Desenvolvimento Econômico e Social (BNDES) e Confederação Nacional dos Transportes (CNT). Também foram realizadas pesquisas de campo para coleta de dados das rodovias bem como mapeamento dos trechos concedidos e de todas as praças de pedágio nos trechos analisados.

A concessão das rodovias federais BR-060 e BR-153 em Goiás, por se tratar de uma apropriação privatista de ativo público, é uma expressão do que Harvey (2005b) denomina acumulação 
por espoliação. Isso porque o regime concessório também implica na apropriação de significativa parcela de recursos públicos, uma vez que sua estruturação depende fundamentalmente do financiamento estatal, a exemplo do que ocorre por meio do BNDES. A concessão dessas rodovias aponta também para processos que caracterizam o uso corporativo do território (Santos e Silveira, 2008). Uso porque, ao prever a duplicação de trechos de pista simples, expressa ações de políticas públicas e privadas para a ampliação de infraestruturas de transporte relevante para as dinâmicas territoriais da região; corporativo posto que o objetivo dessas ações é atender às demandas de grupos corporativos por maior aceleração dos fluxos de pessoas e mercadorias necessários à realização da circulação capitalista e também como garantia de controle de fluxos e apropriação de ativos públicos.

Para compreender a dinâmica dessas rodovias em Goiás, importa observar dois aspectos que caracterizam essas redes de transportes: posição e fluxo. O primeiro se refere à localização (traçado) de ambas as rodovias em relação aos principais municípios de Goiás em termos de produção econômica, comando político bem como a conexão com os principais pontos de escoamento e chegada dos produtos exportados e importados pelo estado. O segundo diz respeito ao volume de tráfego e as atividades econômicas a ele relacionadas, especialmente comércio e prestação de serviços de apoio ao fluxo. Note-se que os dois aspectos possuem uma estreita ligação entre si: ambos apontam para a relação entre redes de transportes e rede urbana, como bem observa Arroyo (2015), uma vez que as rodovias são os meios pelos quais se realizam as trocas de bens e produtos (fluxo material) bem como a hierarquia/influência (fluxo imaterial) entre as cidades.

Mas a posição e a função também suscitam uma discussão sobre o sentido político das rodovias, o que pressupõe discutir o modo como são apropriadas, controladas e como a potencialização de sua fluidez é articulada com a dinâmica econômica dos territórios e com os negócios dos próprios grupos que se apropriam, via concessão ou privatização, dessas infraestruturas. É por isso que o processo de concessão de trechos rodoviários merece ser analisado considerando suas implicações logísticas, mas, especialmente, o modo como a seletividade impacta, por um lado, no crescimento de certas atividades e grupos a elas relacionados, geralmente voltados para uma lógica de circulação extrovertida, haja vista o imperativo que a produção e exportação de commodities tem gerado na vida econômica de países como o Brasil; e por outro, na segregação que essa seletividade gera, deixando regiões e a grande demanda por circulação em escalas locais desassistidas.

\section{As rodovias federais BR-060 e BR-153 em Goiás e seu processo de concessão}

Com extensão territorial de $340.086 \mathrm{~km}^{2}$, Goiás é uma das 27 Unidades Federativas do Brasil e localiza-se na porção central desse país. Em 2018, sua população estimada era de 6.921.161 habitantes (IBGE, 2019). Em 2016, o Produto Interno Bruto (PIB) somou $R \$ 181,69$ bilhões, assim distribuídos: Agropecuária (12,2\%); Indústria (11,9\%); e Serviços (64,9\%). A participação do PIB de Goiás no PIB brasileiro foi de 2,9\%, mantendo o estado na $9^{a}$ posição no ranking nacional (IMB, 2018). Esses dados mostram que, embora o setor de serviços represente a maior fatia, a agropecuária constitui atividade importante na economia goiana, evidenciando, assim, o peso econômico do agronegócio na região. 
As rodovias federais BR-060 e BR-153 formam importantes eixos de ligação do território goiano por servirem diretamente os municípios que possuem os maiores índices de produção econômica e contingente populacional do estado. Conforme a Figura $N^{\circ} 1$, essas rodovias perpassam 6 dos 10 maiores municípios goianos em relação ao PIB: Goiânia $\left(1^{\circ}\right)$, Anápolis $\left(2^{\circ}\right)$, Aparecida de Goiânia $\left(3^{\circ}\right)$, Rio Verde $\left(4^{\circ}\right)$, Itumbiara $\left(6^{\circ}\right)$ e Jataí $\left(7^{\circ}\right)$. Considerando que os três primeiros se destacam pela densidade urbano-industrial e oferta de prestação de serviços enquanto que os demais se caracterizam pela presença de complexos agroindustriais de carnes e grãos, a importância dessas redes de transportes para esses municípios se justifica pelo fato de garantirem o acesso aos bens e serviços bem como o escoamento da produção. Além disso, os municípios de Senador Canedo $\left(9^{\circ}\right)$ e Caldas Novas $\left(10^{\circ}\right)$, dois importantes polos industrial e turístico, respectivamente, do estado de Goiás, servem-se também dessas rodovias. E embora Catalão (5०) e Luziânia ( $\left.8^{\circ}\right)$ sejam perpassados, respectivamente, pelas rodovias federais BR-050 e BR-040, não se pode desconsiderar a importância das BR-060 e BR-153 para esses municípios no contexto da rede urbana regional, uma vez que estão sob a influência dos principais polos ligados por essas rodovias: Brasília e Goiânia.

Figura N01

Posição das rodovias BR-060 e BR-153 em relação aos 10 municípios goianos com maiores PIB's (2014)

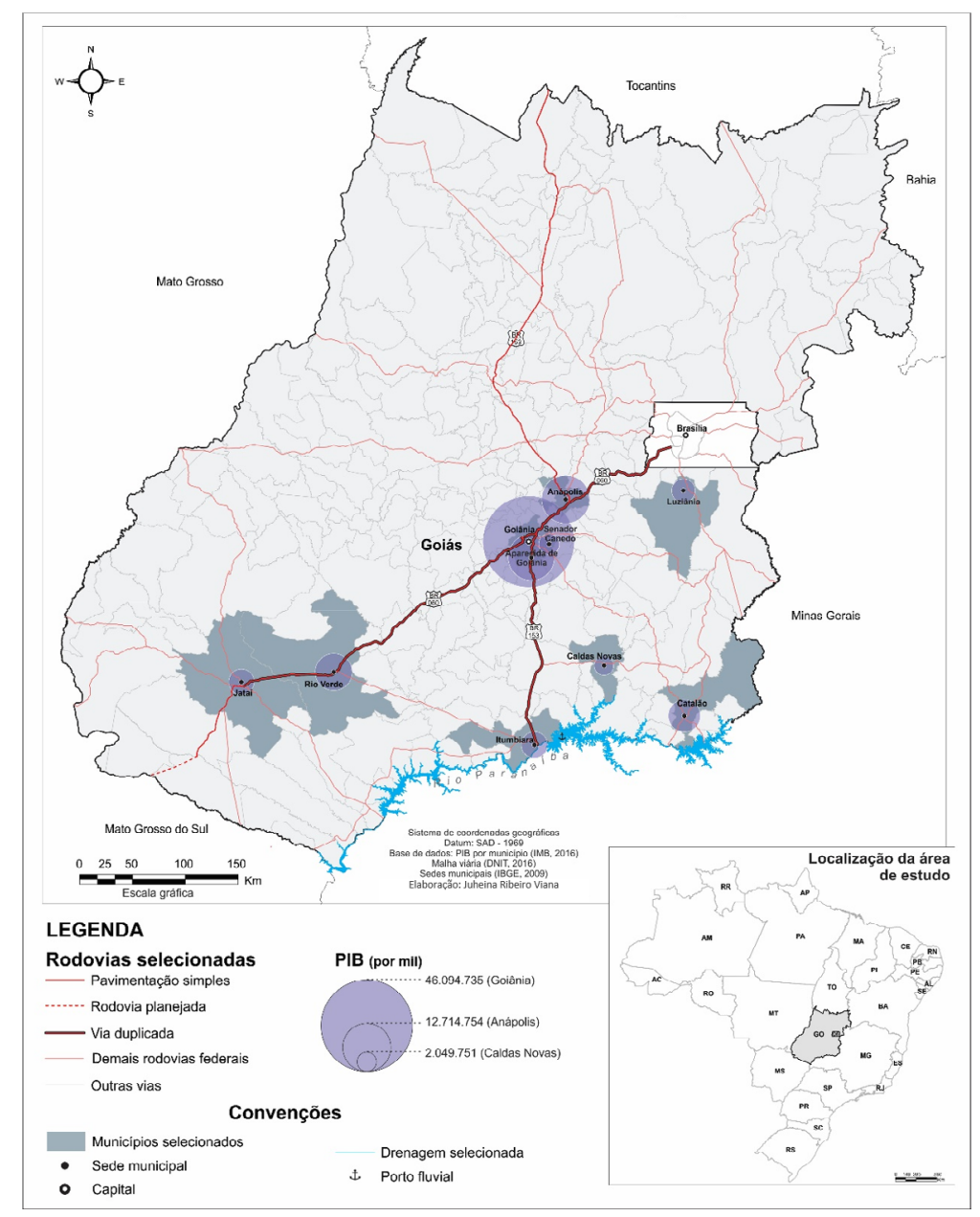

Fonte: Goiás (2016) 
As rodovias federais BR-060 e BR-153 desempenham função relevante em relação à balança comercial goiana, viabilizando o transporte de boa parte do volume de importações e exportações do estado, uma vez que estão direta ou indiretamente conectadas aos principais terminais (portos e aeroportos) de cargas do Brasil.

Dados oficiais mostram que, em 2015, o volume de importação em Goiás somou aproximadamente 3,3 bilhões (US\$ FOB) (Goiás, 2016). Os principais itens foram produtos farmacêuticos $(29,1 \%)$, veículos terrestres $(20,9 \%)$ e adubos fertilizantes $(10,3 \%)$, que juntos somaram aproximadamente $60 \%$ do volume total importado. Os principais pontos de chegada foram porto de Santos (41,5\%), aeroporto de São Paulo $(30,1 \%)$ e porto de Vitória (7,3\%). Nesse cenário, Anápolis se destacou com participação de 50,5\% nas importações goianas, uma vez que, além do Porto Seco Centro Oeste ${ }^{3}$, o município é servido por importantes redes de transportes, a exemplo das rodovias federais BR-060 e BR-153 e das ferrovias Centro-Atlântica e Norte-Sul.

Dado que a rede rodoviária federal e sua conexão com outros modais cumprem relevante função em Anápolis, pode-se concluir que o município está inserido no que Huertas (2013) denominou de nexo territorial. Trata-se de uma conjugação entre a atuação dos agentes transportadores de cargas, a formação do valor de frete e "as amplas condições de fluidez territorial, o que significa situação locacional em trechos privilegiados da rede rodoviária nacional e acesso facilitado a portos, ferrovias, hidrovias e aeroportos" (Huertas, 2013: 41).

Ainda de acordo com os dados oficiais, em 2015, a exportação goiana somou aproximadamente 5,9 bilhões (US\$FOB), sendo que os principais produtos foram do complexo soja ( $30,8 \%$ ), carne $(22,8 \%)$ e minério $(14,2 \%)$. Os três principais pontos de escoamento da produção foram os portos de Santos (55,8\%), Vitória (19,3\%) e Paranaguá $(9,7 \%)$ (Goiás, 2016). Perpassado pela BR-060, Rio Verde foi o município que mais exportou em 2015, movimentando cerca de US\$ 469 milhões. O principal produto exportado foi a soja (em grãos), cuja produção atingiu 744.000 toneladas. Assim, a BR-060 cumpre função relevante no escoamento da produção agrícola, uma vez que se conecta à BR-364, em Jataí, e esta, ao complexo hidroviário de São Simão. Este, por sua vez, integra a Hidrovia Tietê-Paraná, uma das principais vias de acesso ao Porto de Santos. Dada sua conexão com outras rodovias, a BR-060 forma, portanto, um importante eixo nodal de transporte rodoviário no Centro-Oeste brasileiro (Huertas, 2013).

Os dados evidenciam, portanto, a estreita relação entre as rodovias e a dinâmica econômica de Goiás, revelando, sobretudo, a importância da circulação para o funcionamento do território. Embora não seja oficialmente informada a participação das rodovias no volume de importação/ exportação do estado, evidências empíricas apontam para a conclusão de que o transporte dos produtos importados/exportados no estado depende da rede rodoviária federal.

É pela importância territorial e pela crescente circulação que trechos dessas rodovias se tornaram foco do processo de concessão. Do entroncamento da BR-060 com a BR-251 no Distrito Federal, passando por Anápolis e Goiânia, onde a BR-060 coincide com a BR-153, e no percurso desta última entre a capital goiana à Itumbiara, são 630 quilômetros do trecho goiano concedido

Inaugurado em 1999, o Porto Seco Centro Oeste S/A é um terminal alfandegado privado de uso público, destinado à armazenagem e à movimentação de mercadorias importadas, ou destinadas à exportação, sendo utilizado como facilitador das Operações de Comércio Exterior. 
na $3^{a}$ Etapa do primeiro ciclo do Programa de Investimento em Logística. Trata-se do Lote 05 (BR060/153/262 - DF/GO/MG), que além do trecho goiano, também conta com 546 quilômetros da BR-262, do entroncamento com a BR-153 ao entroncamento com a BR-381, no estado de Minas Gerais (Brasil, 2013a). Até o momento da concessão, as condições estruturais do trecho eram: 647,8 quilômetros de pista simples, 528,7 quilômetros de pista dupla e 64,6 de vias marginais (Brasil, 2013b).

O Lote 05 foi licitado em leilão promovido pela ANTT no dia 04 de dezembro de 2013. Conforme o Edital No 004/2013 (Brasil, 2013a), o critério de seleção foi a menor Tarifa Básica de Pedágio (TPB) ofertada, cujo teto era de R\$ 0,05940 por quilômetro. Entre as cinco empresas proponentes, venceu a Triunfo Concessionária das Rodovias Centrais do Brasil (Concebra), que ofereceu Tarifa de $\mathrm{R} \$$ 0,02851 por quilômetro, ou seja, deságio de $52 \%$ em relação ao teto.

Criada em 2014, a Concebra é uma das empresas do grupo Triunfo Participações e Investimentos S.A. Fundada em 1999, a Triunfo S.A é uma corporação de capital aberto, com sede na cidade de São Paulo e listada no Bm\&fBovespa (TPIS3). Com atuação no setor de infraestrutura, principalmente de transportes, o grupo possui 1 concessionária no setor de energia elétrica (Tijoá) e 7 concessionárias no setor de transportes, sendo 5 no segmento rodoviário (Concebra, Concepa, Concer, Econorte e Transbrasiliana), 1 no portuário (Portonave) e 1 no aeroportuário (Viracopos).

Em 31 de janeiro de 2014, a ANTT e a Concebra assinaram o contrato de concessão do lote 5. De acordo com o contrato, o prazo de concessão é de 30 anos contados a partir da data da assunção (assinatura do Termo de Arrolamento e Transferência de Bens), realizada em 05 de março de 2014. A critério do Poder Concedente, o prazo pode ser prorrogado por até 30 anos. Em junho do mesmo ano, o BNDES aprovou empréstimo-ponte ${ }^{4}$ de $\mathrm{R} \$ 1,06$ bilhão para a Concessionária iniciar os investimentos previstos em contrato (Brasil, 2014).

De acordo com o Programa de Exploração da Rodovia (PER), que estabelece condições contratuais do regime de concessão, as ações devem ser dirigidas à fluidez do trânsito bem como segurança e conforto do usuário do Sistema Rodoviário. Por isso o Programa estabelece quatro frentes de ações: I) Recuperação e Manutenção; II) Ampliação de Capacidade e Manutenção de nível de serviço; III) Conservação; IV) Serviços Operacionais (Brasil, 2013b). Destaque para a Frente de Ampliação de Capacidade de Manutenção, que prevê obras de ampliação e melhorias, sendo uma das principais a total duplicação, até o quarto ano da concessão, do trecho de 647,8 quilômetros envolvendo as BR-153 e BR-262 em Minas Gerais.

É importante destacar que os trechos sob concessão em Goiás já se encontravam totalmente pavimentados e duplicados antes mesmo de serem concedidos. O trecho entre Brasília e Goiânia teve sua duplicação concluída em 2007; e entre a capital e Itumbiara, em 2011. Os maiores volumes de tráfego em rodovias federais de Goiás foram registrados justamente nestes dois trechos, sendo o mais movimentado o trecho entre Brasília e Goiânia (DNIT, 2017). Isso significa que foi entregue à iniciativa privada rodovias duplicadas, em boas condições e com os maiores volumes de tráfego do estado. Além da garantia de alta e crescente demanda de consumo, o fato de as

Segundo o BNDES, empréstimo-ponte é uma modalidade de financiamento que antecede a estruturação do financiamento de longo prazo do projeto, ainda em análise pelo Banco. 
rodovias terem sido duplicadas antes da concessão assegura uma rentabilidade ainda maior à concessionária.

Além disso, a garantia contratual de "Recomposição do Equilíbrio Econômico-Financeiro" da concessionária (Brasil, 2013a) corrobora com o fato de que a concessão de rodovias no Brasil tem se tornado um grande negócio aos grupos empresariais. Segundo o contrato, "sempre que atendidas as condições do Contrato e mantida a alocação de risco nele estabelecida, considera-se mantido seu equilíbrio econômico-financeiro" (Brasil, 2013a: 46). Isso significa que, a depender da equação entre o investimento realizado pela Concebra em obras e serviços e o retorno proveniente da cobrança de pedágio e outras receitas, o Poder Concedente garante à empresa as condições financeiras necessárias à exploração das rodovias.

Ainda de acordo com as cláusulas contratuais, a recomposição pode ocorrer também mediante prorrogação do Contrato. Em termos práticos, a ANTT pode aplicar os instrumentos de Desconto ou Acréscimo de Recomposição a partir de avaliações anuais do desempenho da concessão. O desconto será aplicado na hipótese de antecipação da entrega das obras de ampliação de capacidade, a exemplo de duplicação de trechos e construção de desvios em áreas urbanas. O acréscimo poderá ser aplicado na hipótese de atrasos ou inexecução das obras previstas. Em todo caso, o desconto ou acréscimo será aplicado sobre a Tarifa Básica de Pedágio (Brasil, 2014).

A localização estratégica das praças de pedágio também é outro fator que otimiza a capitalização via tarifa. Por estarem situadas entre os principais núcleos urbanos do território goiano, incluindo o eixo Brasília-Anápolis-Goiânia, as quatro praças de pedágio localizadas no estado de Goiás absorvem um alto volume de tráfego de veículos leves e pesados. De acordo com dados da ANTT, em 2017, o volume de tráfego registrado nas quatro praças totalizou 26.882 .863 veículos, sendo 20.239 .657 (75,3\%) da categoria leve (carros de passeio, motocicletas etc.) e 6.643.206 $(24,7 \%)$ da categoria pesado (ônibus, caminhão etc.) (ANTT, 2018).

Dadas as particularidades inerentes às respectivas localizações das praças de pedágio, a exemplo da dinâmica urbana inter e intra-regional (hierarquia urbana, migração pendular, etc.), o tráfego médio mensal registrado em cada praça é diferencial não apenas no tocante à variável quantidade, mas sim também à qualidade (tráfego por categoria de veículo), conforme ilustra a Figura $N^{\circ} 2$.

De acordo com os dados representados na Figura № 2, na praça de pedágio P1, localizada em Alexânia (BR-060, km 43), registrou-se tráfego anual de 6.370.296 veículos, sendo 5.061 .878 leves e 1.308.418 pesados. Sua localização estratégica absorve, principalmente, os fluxos oriundos ou direcionados à Brasília, uma vez que está posicionada entre a capital federal e os municípios goianos de Pirenópolis, Anápolis e Goiânia. Além disso, absorve também o fluxo diário dos habitantes do distrito de Alvorada, município de Alexânia, distante cerca de 15 quilômetros da sede municipal (cidade de Alexânia). Dada a relativa dependência da vila (núcleo urbano do distrito) em relação à cidade, o deslocamento diário dos habitantes locais tornou-se mais oneroso em função do pedágio. Diante disso, em outubro de 2015, parte da população bloqueou a pista nos dois sentidos em protesto contra a cobrança da tarifa (O Popular, 2015). Em resposta às reivindicações, a Concessionária autorizou, temporariamente, a isenção de pedágio para alguns veículos do distrito. 
Figura No 2

Tráfego nos trechos das BR-060 e BR-153 sob concessão em Goiás (2017)

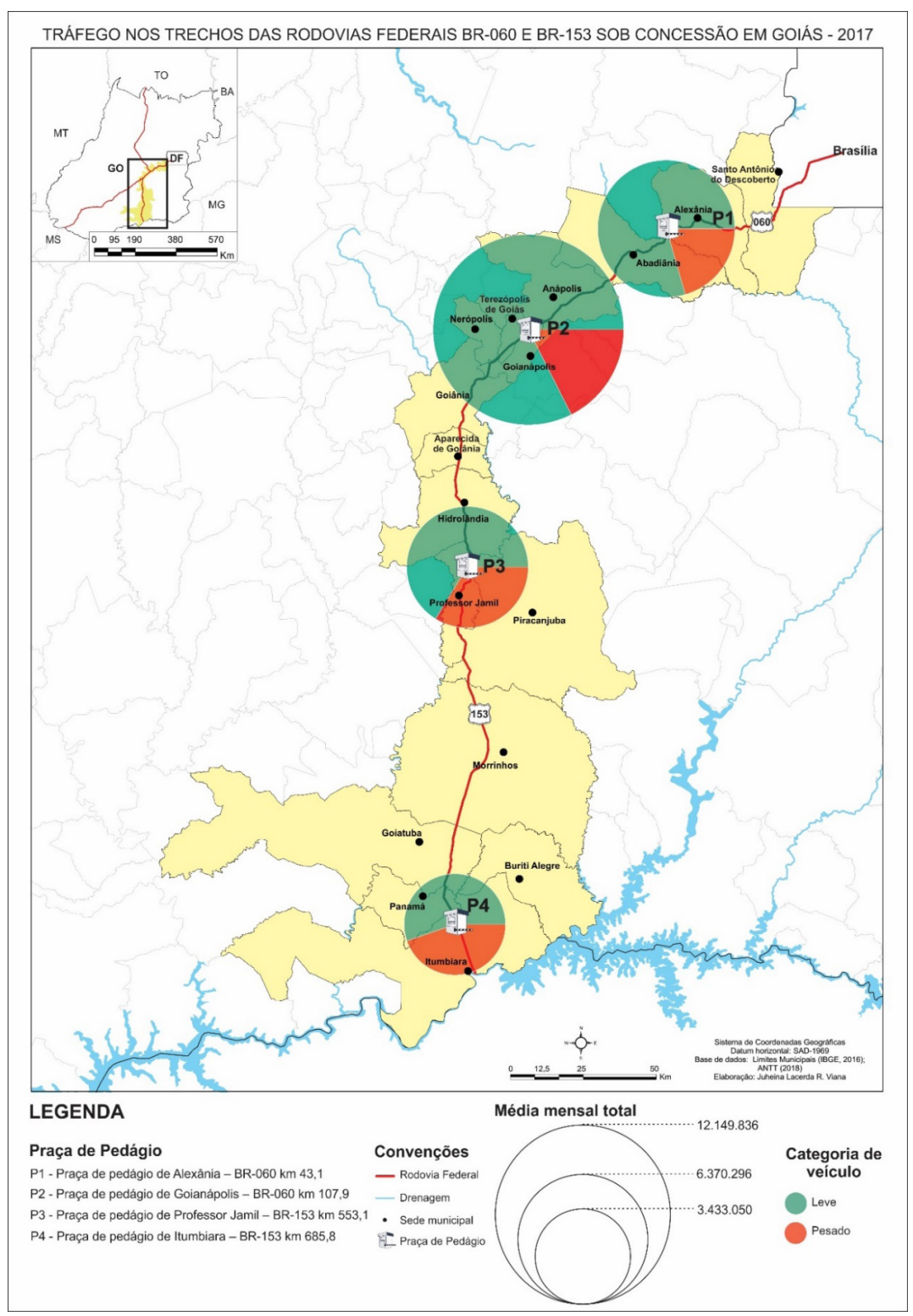

Fonte: IBGE (2016), ANTT (2016).

A praça de pedágio P2, localizada no município de Goianápolis (BR-060, km 107,9), registrou o maior volume de tráfego no período (2017): 12.149 .836 veículos, sendo 10.015.341 leves e 2.134.495 pesados. Destaca-se, nesse caso, a expressiva participação dos veículos leves (82,4\%) em comparação aos pesados (17,6\%). Justifica tal dado o fato de que, estando a praça localizada entre Goiânia e Anápolis (os dois principais polos urbanos regionais), é comum o fluxo diário de trabalhadores e estudantes entre as duas cidades. Ademais, há de se considerar o deslocamento 
cotidiano dos habitantes de Goianápolis, que, dada à proximidade com Anápolis (cerca de 25 quilômetros), também participam dessa migração pendular. Importa observar que a praça de pedágio está posicionada justamente nas proximidades do entroncamento da BR-060 com a rodovia estadual GO-415, principal via de acesso ao núcleo urbano de Goianápolis. Em ambos os casos (praças de Goianápolis e Alexânia), portanto, o fluxo pendular contribui para a elevação da arrecadação via pedágio, pois, estrategicamente, há uma praça no meio do caminho.

Na praça de pedágio P3, localizada no município de Professor Jamil (BR-153, km 553,1), registrou-se tráfego anual de 4.929.681 veículos, dos quais 3.265.207 leves e 1.664.474, pesados. A P3 também possui localização estratégica, uma vez que está instalada próxima ao entroncamento com a rodovia estadual GO-217, principal via de acesso no sentido norte-sul aos municípios de Caldas Novas e Rio Quente - dois dos principais polos turísticos do estado de Goiás e que também figuram entre os mais relevantes do Brasil.

Por fim, localizada no município de Itumbiara (BR-153, km 685,8), a praça de pedágio P4 registrou o menor volume de tráfego no período considerado: 3.433 .050 veículos, sendo 1.897.231 leves e 1.535.819 pesados. Interessante observar que, diferentemente das outras três praças (P1, P2 e P3), na P4 verifica-se maior participação proporcional do tráfego de veículos pesados, que representam $44,5 \%$ do volume total. Entre os fatores que justificam tal dado, destaca-se o intenso fluxo de caminhões em função da presença de agroindústrias na região, a exemplo da Central Energética de Morrinhos (em Morrinhos), que processa cana-de-açúcar, e da Caramuru (em Itumbiara), cujas atividades envolvem, basicamente, o processamento de soja. A região também se constitui como importante nó do sistema rodoviário do Centro-Oeste brasileiro. Além disso, há de se considerar o peso da conexão imediata com os trechos mineiros e paulista da BR-153. Neste trecho, inteiramente sob concessão de outra concessionária (Transbrasiliana) do grupo Triunfo S.A., verificou-se, em 2017, o maior percentual proporcional de tráfego de veículos pesados ${ }^{5}$ dentre todas as rodovias administradas pelo grupo, fato que aponta para a existência de um intenso fluxo de cargas no eixo dessa rodovia.

Além da localização das praças de pedágio, o conjunto de estratégias da concessionária para se beneficiar do fluxo de veículos envolve também a implantação de bloqueios de acesso à rodovia por meio de desvios ou estradas vicinais próximas às praças ${ }^{6}$. Desse modo, a empresa garante que um maior número de veículos desemboque inevitavelmente nas cabines de cobrança, resultando em aumento da receita tarifária. Por estes motivos, como bem observam Arrais, Castilho e Aurélio Neto (2016), a concessão de rodovias federais representa um grande negócio para a iniciativa privada no Brasil.

Dos 23,7 milhões de veículos passantes no trecho paulista da BR-153 em 2017, 15,8 milhões (66,5\%) enquadram-se na categoria "pesados", enquanto que aproximadamente 7,9 milhões (33,5\%) na categoria "leves" (TRIUNFO, 2018).

Tal prática foi relatada por moradores do município de Abadiânia, próximo à praça de Alexânia (BR-060, km 43,1), durante o trabalho de campo realizado nas rodovias em 10 de julho de 2017. 


\section{A acumulação por espoliação}

Sabe-se, com Marx $(2013 ; 2014)$, que a acumulação é um processo dinâmico e central no modo de produção capitalista. O fato é que, de acordo com esse autor, a acumulação capitalista se realiza por meio de estratégias criadas pelo próprio capital. A apropriação privada de bens públicos é uma delas.

Harvey (2005b) salienta que alguns mecanismos da acumulação primitiva enfatizados por Marx (2013) foram aprimorados e, por isso, desempenham hoje um papel mais forte que no passado. Dentre eles destacam-se o sistema de crédito e o capital financeiro, que, por seu caráter especulativo e predatório, constituem meios de predação, fraude e roubo (Harvey, 2005b). Para o autor, o caráter predatório da acumulação é um processo contínuo e que foi internalizado pelo próprio capitalismo. Daí sua manifestação nos dias atuais sob as mais variadas formas, especialmente por meio da privatização e da concessão.

Nesse sentido, Harvey (2013) sustenta que, em vez de acumulação primitiva, prefere denominar esse processo de acumulação por espoliação (ou despossessão). Além do aprimoramento das formas de acumulação primitiva, Harvey (2005b) observa que foram criados novos mecanismos de acumulação por espoliação. Destacam-se, entre outros, a corporativização e privatização de bens públicos, como universidades, a água, a energia e outros serviços e utilidades públicas, ao que podemos acrescentar as redes de transportes. Daí que, conforme argumenta Harvey (2005b: 123), "o poder do Estado é com frequência usado para impor esses processos mesmo contrariando a vontade popular".

A pertinência desse argumento é evidente no caso da concessão das rodovias federais BR060 e BR-153 em Goiás. Apesar de algumas audiências públicas promovidas pela ANTT, é fato que a transferência à iniciativa privada do direito de exploração dessas rodovias não levou em consideração a vontade popular, especialmente quando se trata dos sujeitos diretamente afetados por esse processo. Em Terezópolis de Goiás, por exemplo, os comerciantes instalados às margens das rodovias reclamam da pressão exercida pela Concebra para que deixem o local. Isto porque o contrato de concessão garante à concessionária o monopólio da Faixa de Domínio7 (Brasil, 2013a).

Além disso, sequer foi considerado o dispêndio financeiro dos trabalhadores que, dada a necessidade de deslocamento diário de uma cidade a outra em função do trabalho, tiveram o custo de transporte elevado devido ao pagamento de pedágio. $O$ alto volume de tráfego registrado na BR-060/153 entre Goiânia e Anápolis - média de 25.510 veículos/dia (DNIT, 2017) - é, em certa medida, proporcionado por essa migração pendular. Como mencionado anteriormente, em 2015 moradores do Distrito de Alvorada, município de Alexânia-GO, queimaram pneus e bloquearam as duas pistas da BR-060 ( $\mathrm{km} \mathrm{43)} \mathrm{em} \mathrm{protesto} \mathrm{contra} \mathrm{a} \mathrm{implantação} \mathrm{da} \mathrm{praça} \mathrm{de} \mathrm{pedágio} \mathrm{entre} \mathrm{a}$ vila e a sede do município. A justificativa dos manifestantes se baseava no ônus do deslocamento entre as duas localidades, uma vez que os moradores da vila dependem, em grande medida, da

Segundo o Departamento Nacional de Infraestrutura de Transportes (DNIT), "define-se como 'Faixa de Domínio' a base física sobre a qual assenta uma rodovia, constituída pelas pistas de rolamento, canteiros, obras-de-arte, acostamentos, sinalização e faixa lateral de segurança, até o alinhamento das cercas que separam a estrada dos imóveis marginais ou da faixa do recuo" (DNIT, 2017). 
cidade em razão dos produtos e serviços nela concentrados. A espoliação do direito de ir e vir livremente caracteriza, portanto, o caráter privatizante da concessão das rodovias.

Mas o papel do poder público não se restringe a garantir a imposição desse processo contra a vontade popular. Ao Estado também cabe a função de viabilizar financeiramente essa imposição, uma vez que a implantação da concessão é financiada principalmente por meio de recursos públicos. No caso em tela, o financiamento foi garantido pelo Banco Nacional do Desenvolvimento Social e Econômico (BNDES). Em junho de 2014, o BNDES aprovou empréstimo-ponte ${ }^{8}$ no valor de R $\$$ 1,06 bilhão à Concebra (Brasil, 2014). Em fevereiro de 2016, o Banco aprovou o financiamento de longo prazo no valor de $\mathrm{R} \$ 3,58$ bilhões à Concessionária, sendo $\mathrm{R} \$ 2,51$ bilhões na modalidade direta e $R \$ 1,07$ bilhão na modalidade indireta, com repasses de agentes financeiros (Brasil, 2016). Contundo, até o final de 2016 o financiamento a longo prazo ainda não havia sido executado e, por isso, o empréstimo-ponte, cujo prazo de amortização vencera no dia 15 de dezembro daquele ano, não foi totalmente amortizado. Em 31 de dezembro de 2016, o saldo da dívida da Concebra junto ao BNDES era de R\$824,99 milhões (Concebra, 2017).

Isso demonstra que a espoliação não se restringe apenas à apropriação privada das rodovias em si mesmas. Os grupos privados também se apropriam, de forma direta, de recursos financeiros públicos para sua reprodução. Daí ser o sistema financeiro um dos grandes trampolins de predação, fraude e roubo, uma das características marcantes do capitalismo contemporâneo (Harvey, 2005b). Desse modo, a concessão das BR-060 e BR-153 em Goiás caracteriza um processo perverso: após construir e melhorar (pavimentação e duplicação) as rodovias, o Estado as entrega aos grupos privados e, como se não bastasse, ainda oferece as condições financeiras necessárias (financiamento) para a apropriação privada. Trata-se, por assim dizer, de um processo espoliativo-acumulativo muito mais perverso que a "privatização" em sentido jurídico, pois se realiza sob a tutela do Estado.

Além do entreguismo e do financiamento público, o caráter contraditório desse processo é caracterizado também pelos investimentos estatais realizados no objeto concedido mesmo após o início da concessão. Sustentado juridicamente pela Lei 11.709/2004 - Lei das PPP's (Parcerias Público-Privadas) - o regime concessório das BR-060 e BR-153 em Goiás enquadra-se na modalidade "concessão patrocinada" (Brasil, 2004), uma vez que, além da arrecadação por meio da cobrança de pedágio, a concessionária recebe aporte financeiro público para a duplicação da malha rodoviária. Em 2016, a receita de construção foi na ordem de $\mathrm{R} \$ 200,043$ milhões, o equivalente a $36,32 \%$ da receita operacional líquida da Concessionária (Concebra, 2017).

Ao analisar os investimentos públicos federais em infraestruturas de transportes sob concessão no Brasil, Bittencourt (2009) ressalta a contradição verificada nessa relação. A partir da década de 1990, conforme bem observa o autor, as concessões de redes de transportes e outros bens e serviço públicos se basearam na suposta necessidade de reposicionamento do Estado em relação a setores estratégicos da economia - "necessidade" essa expressa nos objetivos fundamentais do Plano Nacional de Desestatização (PND). Nesse sentido, Bittencourt (2009) destaca que toda a argumentação em prol das concessões se baseava, entre outras justificativas, em necessidades de ordem fiscal (insuficiência arrecadatória, incapacidade e outras prioridades de

8 O empréstimo-ponte constitui uma modalidade de financiamento que antecede a estruturação do financiamento de longo prazo do projeto. 
investimentos etc.) e microeconômica (otimização dos custos, execução de obras inacabadas, inovações tecnológicas etc., resultantes do investimento privado). O caráter contraditório desse processo reside no fato de, mesmo após a aprovação da concessão, o Estado continuar a investir recursos públicos nos bens e serviços concedidos. Por esta razão, os questionamentos de Bittencourt (2009) são contundentes:

Ora, uma realização de investimentos estatais de vulto nos mesmos sistemas logísticos submetidos à concessão representa o oposto de toda uma argumentação que sustentou essa mesma concessão: se o Estado não tem recursos para investir, como então está investindo (e em não pequena escala)? Se como inversões estatais são ineficientes ou não têm capacidade de alavancagem financeira ou tecnológica, por que são feitas? (Bittencourt, 2009: 36)

O autor também adverte que não está a sustentar a inconveniência da abertura política ao capital privado no setor de transportes. Não obstante, salienta a contradição entre os fundamentos desta política e a "permanência de um esforço fiscal considerável para inversões nos mesmos bens para os quais o investimento privado foi apontado como única forma de recuperação físico e operacional" (Bittencourt, 2009: 36). O fato é que, além de contradizer os próprios argumentos em prol da concessão das rodovias, o aporte financeiro do Estado destinado à gestão privada dessas redes contradiz também toda a lógica do planejamento orçamentário público e, portanto, agrava o grau de perversidade do regime concessório.

Cabe ainda ressaltar que o processo de concessão de redes de transportes resulta das políticas neoliberais implantadas no Brasil a partir da década de 1990. As políticas neoliberais constituem, segundo Harvey (2005b), o símbolo da acumulação por espoliação. Como a privatização e liberalização do mercado representam, de acordo com o autor, o mantra do neoliberalismo em sentido amplo, a consequência é a transformação das políticas de Estado em "expropriação das terras comuns". Desse modo, "ativos de propriedade do Estado ou destinados ao uso partilhado da população em geral foram entregues ao mercado para que o capital sobreacumulado pudesse investir neles, valorizá-los e especular com eles" (Harvey, 2005b: 130).

Mas, afinal, como o processo de acumulação por espoliação se expressa por meio da concessão? Para responder a esta questão, é preciso compreender a função do processo espoliativo. Segundo Harvey (2005b),

o que a acumulação por espoliação faz é liberar um conjunto de ativos (incluindo força de trabalho) a custo muito baixo (e, em alguns casos, zero). O capital sobreacumulado pode apossar-se desses ativos e dar-Ihes imediatamente um uso lucrativo (Harvey, 2005b: 124).

A função da espoliação é, de acordo com Harvey (2005b), liberar ativos para serem lucrativamente apropriados pelos excedentes de capital e, desse modo, resolver o problema da sobreacumulação. Na Inglaterra, por exemplo, a privatização de bens públicos como a habitação social, as telecomunicações, os transportes etc., abriu campos passíveis de apropriação pelo capital sobreacumulado (Harvey, 2005b). No caso do Brasil, uma análise do processo de privatização de setores estratégicos da economia (transportes, energia, comunicação etc.), desencadeado, 
sobretudo, a partir da década de 1990, pode levar a constatação de processo semelhante ao do caso britânico.

Considerando a condição dos trechos das BR-060 e BR-153 sob concessão em Goiás, a liberação de ativos se mostrou lucrativa na medida em que foi baixo o custo de implantação do regime concessório. Isto porque, apesar da previsão de investimentos na ordem de $R \$ 3,98$ bilhões nos primeiros cinco anos de concessão (Concebra, 2017), a necessidade de gastos com recuperação e manutenção nos referidos trechos nesse período é ínfima, uma vez que já se encontravam totalmente pavimentados e duplicados antes da concessão.

Nessa perspectiva, as rodovias federais administradas pelo Estado brasileiro constituem ativos públicos subvalorizados em termos capitalistas. A subvalorização pode ser considerada efeito de uma suposta crise no sistema de financiamento público de infraestrutura de transporte. A crise, por sua vez, é caracterizada pela queda dos investimentos em ampliação e melhoramento da maIha rodoviária federal. Segundo dados da CNT (2017), de 2004 a 2016, o governo federal investiu $\mathrm{R} \$ 89,4$ bilhões, o equivalente a 70,4\% do total autorizado no período. Além disso, de 2001 a 2016, os investimentos públicos federais no setor representam, em média, 0,16\% do Produto Interno Bruto (PIB) brasileiro, volume considerado muito aquém das necessidades do setor (CNT, 2017).

Uma análise mais detalhada dos dados permite constatar que, embora a média de investimento seja relativamente baixa, houve uma significativa ascensão do percentual investido de 2003 a 2010, passando de 0,05\% para 0,26\% do PIB (CNT, 2017). Nesse mesmo período, Campos Neto, Paula e Souza (2011) apontam que o montante investido saltou de $\mathrm{R} \$ 1,3$ bilhão para 10,3 bilhões, um incremento de aproximadamente $700 \%$. Não por acaso a alta dos aportes públicos em rodovias federais coincidir com o período de preparação da $3^{3}$ etapa do Procrofe ${ }^{9}$. Por outro lado, de 2011 a 2016, a taxa de investimento decaiu de 0,25\% para 0,16\% do PIB (CNT, 2017). Em face disso, pode-se inferir que a "crise" de investimento público em rodovias - ou o seu oposto, isto é, o incremento de aportes - possui relação direta com as oportunidades de investimento privado, uma vez que o sucesso deste depende do insucesso daquele. Dito de outro modo, a ausência ou insuficiência de investimentos públicos diretos dá margem para a alegação da necessidade dos investimentos privados.

Não por acaso, Harvey (2005a) sustenta que as crises cumprem uma função importante no desenvolvimento capitalista, pois lhe impõem algum tipo de ordem e racionalização. Para o autor, essa racionalização apresenta um custo social e provoca sérias consequências, a exemplo de falências, colapsos financeiros, inflação, queda dos salários reais, perda de direitos trabalhistas e desemprego. Por outro lado, ainda de acordo com o autor, a racionalização forçada pode gerar também a luta de classes e os movimentos revolucionários. O fato é que, sempre que necessário para a sustentação do sistema capitalista, serão criadas "condições apropriadas para a renovação da acumulação" (Harvey, 2005a: 47). As crises são, portanto, momentos oportunos para a renovação do processo de acumulação de capital.

Nesta etapa, conforme demonstrado no capítulo 1, o governo federal outorgou a concessão de 9 lotes rodoviários, dentre os quais o lote BR060/153/262 (DF/GO/MG), totalizando 5.348,7 quilômetros de rodovias concedidas à iniciativa privada. 
Ainda de acordo com Harvey (2005a: 47), cada crise representa "uma mudança no processo de acumulação para um nível novo e superior". Na elaboração de um novo nível de acumulação caracterizado pelo aumento da demanda efetiva por produtos, o autor destaca a articulação de quatro aspectos: 1) penetração de capital em novas atividades econômicas; 2 ) criação de novos desejos e novas necessidades; 3 ) facilitação e estímulo para o crescimento demográfico; e 4) expansão geográfica para novas regiões. Desse modo, explica o autor,

em cada um desses aspectos, ou pela combinação deles, o capitalismo é capaz de criar uma nova oportunidade para a acumulação. Os três primeiros itens podem ser vistos como matéria de intensificação da atividade social, dos mercados e das pessoas numa específica estrutura espacial. O último item suscita a questão da organização espacial e da expansão geográfica como produto necessário para o processo de acumulação (Harvey, 2005a: 48, grifo nosso).

Harvey (2005a) ressalta que os processos de intensificação e de expansão geográfica não são necessariamente separados e que é possível um equilíbrio entre eles. Contudo, o foco de sua análise está na dimensão espacial do processo de acumulação, uma vez que, «quanto mais difícil se torna a intensificação, mais importante é a expansão geográfica para sustentar a acumulação de capital» (Harvey, 2005a: 48). A partir desta premissa, o autor identifica a circulação de capital como elemento-chave da relação entre a teoria marxista da acumulação e a produção de estruturas espaciais. Daí ser a circulação do capital uma condição imprescindivel para sua acumulação (Marx, 2014). Em outros termos, sem circulação não há acumulação (Harvey, 2005a).

Importa ressaltar, conforme argumenta Marx (2013), que a produção de capital passa por sucessivas fases dentro da esfera da circulação. Isto significa, explica o autor, que o primeiro passo para a transformação do valor em capital é a conversão da forma em meios de produção e força de trabalho. Em seguida, dos meios de produção juntamente com a força de trabalho são produzidas mercadorias que, constituídas de mais-valia, serão trocadas por dinheiro. Este, então, deve ser convertido em capital, repetindo-se assim o ciclo. Esse movimento circular, que se realiza sempre por meio de fases sucessivas constitui, portanto, a circulação do capital (Marx, 2013).

Segundo Harvey (2005a), a circulação possui dois aspectos: 1) movimento físico de mercadorias local de produção para o local de consumo; 2) custo real ou implícito referentes ao tempo gasto e às mediações sociais necessárias ao deslocamento de mercadorias até o consumidor final. Valendo-se de Marx, Harvey (2005a) ressalta que o primeiro aspecto integra o processo produtivo e, por isto, gera valor; o segundo, no entanto, é um custo necessário e, desse modo, não gera valor. Diante disso, as redes de transportes assumem uma importância fundamental para a acumulação, pois, ao viabilizarem o aspecto material (movimento físico) da circulação, são potencialmente geradoras de mais-valia (Harvey, 2005a).

Nesse processo, segundo Harvey (2005a), o custo do transporte é uma variável importante na medida em que a troca acumulada é sensível a este custo. Daí a tendência, segundo o autor, das forças produtivas do capital em reduzir o custo de circulação por meio do aperfeiçoamento dos transportes - e também da comunicação -, que, no contexto da acumulação em geral, torna-se inevitável e necessário. Isso porque, conforme assinala Harvey (2005a: 50), “o imperativo da acumulação implica consequentemente no imperativo da superação das barreiras espaciais". 
A superação das barreiras espaciais, segundo Harvey (2005a), significa a criação de novos espaços para acumulação, tornando este processo geograficamente expansível. Por isso a importância da redução dos custos de circulação por meio do aperfeiçoamento - poder-se-ia também acrescentar a produção - das redes de transportes. Caso contrário, a expansão geográfica da acumulação aumentaria o tempo de giro do capital - este igual o tempo de produção mais o tempo de circulação -, cujo resultado seria a proporcional redução da mais-valia (Harvey, 2005a).

A variabilidade do tempo de circulação é condicionante no processo de produção de mais-valia, explica Marx (2014). Daí a necessidade de sua progressiva anulação ou redução. O autor também explica que, quanto mais o tempo de circulação se aproxima de zero, tão mais funciona o capital e tão maiores se tornam sua produtividade e produção de mais-valia. Por este motivo, o aumento da velocidade de circulação influi diretamente na intensificação da acumulação. Em síntese, a importância da circulação para o processo de acumulação pode ser traduzida nos seguintes termos:

a criação de valor depende da capacidade de realizá-la através da circulação. O insucesso da realização de valor significa, simplesmente a negação do valor criado potencialmente na produção. Portanto, se a esfera da circulação não se expande, a acumulação para (Harvey, 2005a: 72-73).

Onde se encaixa o processo de concessão nessa relação? Primeiro é preciso lembrar que trata-se de uma forma legal de controle privado de redes de transportes e que, em países como o Brasil, se constitui como grande negócio. Por isso, a concessão é estratégica tanto para o controle como para a espoliação. No caso de sua relação com a circulação e acumulação, a concessão acaba tendo como função a garantia da regularidade dos fluxos por meio da criação ou manutenção de condições materiais de tráfego. Criação quando da pavimentação e/ou duplicação de determinados trechos. Manutenção quando a tarefa é apenas conservar essas formas de melhoramento das vias, cuja implantação já fora feita pelo Estado antes da entrega à iniciativa privada. Este é o caso dos trechos das BR-060 e BR-153 em Goiás. A criação ou manutenção dessas condições são fundamentais para a circulação de mercadorias, pois favorecem a redução do seu tempo de realização, potencializando assim a intensificação da acumulação. É nessas circunstâncias que o setor de transporte se mostra atrativo para o capital.

Segundo Harvey (2005a), as redes de transportes tendem a ser produzidas e melhoradas por intermédio do Estado, e não pelo investimento direto de capital privado, salvo em condições atrativas para este. Embora o autor não explicite tais condições, presume-se que uma delas seja a grande probabilidade de acumulação por meio da apropriação privada dessas redes, seja na forma de privatização ou concessão. No caso das concessões rodoviárias em vigor no Brasil, o potencial de acumulação das concessionárias é evidentemente significativo. Tal como bem observou Huertas (2013), se, por um lado, representantes dessas empresas se queixam das dificuldades financeiras durante os primeiros dez anos da concessão, por outro, parecem se esquecer que o prazo médio dos contratos é de 25 anos e que, por isso, vislumbra-se um cenário provável de alavancagem dos lucros por mais de uma década.

Ademais, durante a gestão de Michel Temer (2016-2018), foi promulgado no Brasil uma normativa que favorece a rearticulação das empresas diante das supostas dificuldades de gerenciamen- 
to dos contratos. Trata-se da Lei 13.448/2017, que permite a prorrogação e relicitação dos contratos de concessão de rodovias federais - bem como de ferrovias, portos e aeroportos vinculados à esfera federal. Tal normatização caracteriza o afloramento de uma tendência - estratégica, vale salientar - no âmbito das concessões: a devolução à União ou a transferência para outras empresas das rodovias em que se verifica o descumprimento das obrigações contratuais assumidas pelas concessionárias. Dos quatro contratos envolvendo rodovias federais em Goiás, um foi cassado (BR-153 entre GO e TO), dois estão em processo de devolução (BR-040) e transferência (BR-050) e o outro (que se refere às rodovias em questão, BR-060/153) possui chance significativa de ser revisto, uma vez que, tal como alegado pela própria concessionária (Concebra), "a relicitação é uma alternativa" (O Popular, 2018). O fato é que a concessão expressa a estratégia capitalista de acumulação via espoliação.

Nessa perspectiva, e dada a posição estratégica das rodovias federais BR-060 e BR-153, a concessão dessas redes de transportes expressa também um outro processo que, em certa medida, está correlacionado à acumulação via espoliação. Se a circulação de mercadorias - que significa também a circulação de capital - é tão importante no processo acumulativo, torna-se elementar a criação de condições para a sua realização em uma velocidade cada vez maior. Em outros termos, o imperativo da acumulação capitalista impõe a necessidade da produção de fluidez, caracterizando o uso corporativo do território.

\section{Considerações finais: a concessão termina por adensar o uso corporativo do território}

Quando North (2018: 32) diz que "o poder coercitivo do Estado tem sido empregado de forma desfavorável ao crescimento econômico, mas que seria difícil sustentar trocas complexas sem uma terceira parte que faça cumprir os acordos", deixa de considerar realidades como a do Brasil, onde há um descompasso entre o processo de concessão e/ou de privatização e de regulamentação/fiscalização. O caso da Lei 13.448/2017 mencionado no tópico anterior evidencia isso. Além de toda vantagem à concessionaria observada nos contratos e de todo apoio vindo do Estado por meio, por exemplo, de financiamentos e garantia do equilíbrio econômico-financeiro da empresa, ainda há revisão de leis e uma complexa amarração (haja vista a prática de lobbys) que faz do Estado um verdadeiro meio de ascensão de grupos empresariais e sustentáculo de seus interesses.

Em países como o Brasil, portanto, o poder do Estado não é coercitivo com concessionárias e empresas privadas como prevê os acordos e contratos. Além de se constituírem como caminho para a acumulação por espoliação, as concessões de grandes infraestruturas no Brasil terminam por adensar o uso corporativo do território e encontram um ambiente de regulação frouxa que desemboca em fiscalização frágil e, consequentemente, em excessiva impunidade. Isso favorece ainda mais a seletividade dos fluxos e as desigualdades regionais.

Sobre isso, Arroyo (2015) destaca que, a partir da produção de formas destinadas à garantia de fluidez e da criação de normas destinadas à regulação da "porosidade territorial", Estados nacionais e corporações envolvidos no comércio internacional têm participação importante nos processos de competição, cooperação e controle do território, sendo, portanto, decisivos no seu uso. Convém ressaltar que porosidade territorial significa, na definição de Arroyo (2015: 45), a "qualidade dos terri- 
tórios nacionais que facilita sua relação com o exterior, a partir de uma base institucional e normativa incumbida da regulação do movimento". Segundo a autora, há, por um lado, ações institucionais do poder público que, por meio de leis e outras estratégias normativas, facilita a relação do território nacional com o mercado externo, enquanto que, por outro, verifica-se ações corporativas, como associações setoriais, prática de lobbies etc., articuladas com as ações públicas.

Ou seja, as ações estatais estão voltadas para a formação de corredores de exportação especializados e eixos de desenvolvimento que aumentam a fluidez territorial e dinamizam determinados setores econômicos e áreas do território brasileiro. Daí que, conforme anota Castillo (2011: 339), a logística se torna "a expressão de uma organização e de um uso do território, voltados, na linguagem corporativa (que também é da grande mídia), para a superação dos gargalos da circulação", de modo a evitar os apagões logísticos e reduzir o custo país. Trata-se, portanto, de um uso corporativo do território baseado na seletividade espacial.

Ao analisar os serviços de transporte rodoviário de cargas no Brasil, Huertas (2013) defende que, no plano operacional, a inserção e o tratamento de informações em tempo real no planejamento logístico tornaram-se um imperativo - informações essas que, segundo o autor, significam ações também em tempo real. Desse modo, "essa determinação faz com que o tempo de resposta do embarcador e do comprador seja cada vez menor, fato que exige maior fluidez do transportador (Huertas, 2013: 97).

Diante disso, o controle privado das rodovias implica, entre outros aspectos, o emprego de tecnologias de informação que monitoram - inclusive em tempo real - o tráfego em todo o trecho sob concessão. O uso das tecnologias informacionais, sem as quais a logística seria inviável (Huertas, 2013), representa transformações técnicas subordinadas ao imperativo da fluidez territorial e que contribuem para o seu controle.

É nesse contexto que a ANTT publicou, em meados de 2017, uma normativa que trata da fiscalização eletrônica remota do transporte rodoviário de cargas no país. A Resolução n 5.379/2017 estabelece que todas as concessionárias que administram rodovias federais façam adesão ao novo sistema de fiscalização, cuja uma das exigências é a instalação de equipamentos de monitoramento remoto em todas as praças de pedágio (ANTT, 2017).

Ainda de acordo com a ANTT (2017), a fiscalização eletrônica remota do transporte de cargas, sob responsabilidade da Agência, faz parte do programa Canal Verde Brasil, Rede Logística Inteligente, uma política voltada para a desburocratização e redução do custo logístico, cujo principal objetivo é aumentar a competitividade dos produtos brasileiros no mercado internacional.

A lógica do Canal Verde Brasil é a percepção eletrônica e permanente de fluxos de transporte nos principais corredores logísticos do Brasil e a integração entre bancos de dados da ANTT e de parceiros estratégicos para agregação de valor ao dado captado, para fins regulatórios, tributários, de segurança, e, sobretudo, de produção de dados, informações e conhecimento acerca dos fluxos logísticos (ANTT, 2017, n.p.).

Diante do exposto, torna-se evidente a trama política envolvendo o poder público e a iniciativa privada com o objetivo de, por meio de sistemas logísticos, produzir, controlar e utilizar de 
forma privilegiada informações relativas ao fluxo de mercadorias. E a concessão, conforme já demonstrado, representa um fator importante nesse processo. Trata-se, portanto, de uma evidência incontestável da articulação entre Estado e iniciativa privada voltada à produção e, sobretudo, ao controle da fluidez territorial.

Se a produção e o controle da fluidez são características do uso corporativo do território, a apropriação privada das redes de transportes por meio da concessão e o uso privilegiado de informações dos fluxos por meio de sistemas logísticos integrados caracterizam ações de grupos hegemônicos, chanceladas pelo Estado, cujo objetivo é tão somente o atendimento às exigências corporativas orientadas por uma lógica vertical. Desse modo, enquanto expressões de verticalidades, tais exigências se efetivam em detrimento de demandas horizontais por melhores condições de infraestrutura de transporte.

Enquanto se melhora (pavimenta, duplica, recupera) eixos estratégicos para a circulação e também para a acumulação espoliativa - como no caso dos trechos da BR-060 e BR-153 sob concessão em Goiás, caracterizando, assim, uma seletividade espacial -, verifica-se em várias partes do território brasileiro a deterioração de rodovias de ligação em péssimas condições de tráfego ou até sem pavimentação, conforme apontado na Pesquisa CNT de Rodovias (CNT, 2017). Há de se considerar também o péssimo estado das estradas vicinais, que, enquanto parte da rede, desempenham importante função nas interações espaciais - alimentando, inclusive, os eixos troncais. $O$ resultado, tal como observam diversos autores (Castillo, 2011; Huertas, 2013; Castilho, 2016), é a permanência - e até o agravamento - das desigualdades regionais.

Um exemplo de implicação regional dessa lógica privatista-espoliativa e seletiva é a segregação socioespacial envolvendo os usuários frequentes dos trechos das BR-060 e BR-153 sob concessão em Goiás. Seja para estudar ou trabalhar, centenas de pessoas se deslocam diariamente entre e principalmente para os principais centros urbanos perpassados por essas rodovias: o eixo Goiânia-Anápolis-Brasília.

No trecho da BR-060 entre Anápolis e Brasília, por exemplo, a praça de pedágio absorve também o fluxo diário dos habitantes do distrito de Alvorada, município de Alexânia, distante cerca de 15 quilômetros da sede municipal. Dada a relativa dependência da vila (núcleo urbano do distrito) em relação à cidade, o deslocamento diário dos habitantes locais tornou-se mais oneroso em função do pedágio. Diante disso, em outubro de 2015, parte da população bloqueou a pista nos dois sentidos em protesto contra a cobrança da tarifa (O POPULAR, 2015). Em resposta às reivindicações, a Concebra autorizou, temporariamente, a isenção do pedágio para alguns veículos do distrito previamente cadastrados junto à concessionária.

Outro caso refere-se à praça de pedágio localizada na BR-153, no município de Professor Jamil. Sua localização é estratégica, uma vez que está instalada próxima ao entroncamento com a rodovia estadual GO-217, principal via de acesso no sentido norte-sul aos municípios de Caldas Novas e Rio Quente - dois dos principais polos turísticos do estado de Goiás. A tarifação dos deslocamentos cotidianos em função do pedagiamento das vias implica, portanto, uma oneração adicional e compulsória a trabalhadores, estudantes, turistas e demais usuários que dinamizam a rede urbana regional. 
Nessa perspectiva, é fundamental que a fluidez no Brasil seja produzida não apenas baseada numa lógica de circulação extrovertida, mas também voltada ao desenvolvimento socioeconômico nas escalas local e regional. Isso implica considerar, por exemplo, além do planejamento direcionado à multimodalidade, o desenvolvimento e aperfeiçoamento das rodovias de ligação e estradas vicinais que contribuem para o fluxo e para a vida de relações que dão funcionalidade ao território. Os transportes têm sido instrumento de reafirmação do privilégio e do crescimento de grupos restritos, mas também podem (e devem) ser condição de acesso, de integração, de desenvolvimento e de ampliação das inter-relações e das trocas nas mais variadas escalas.

\section{Referências}

ANTT (Agência Nacional de Transportes Terrestres). Concessões Rodoviárias. 2017. Disponível em: http://www.antt.gov.br/index.php/content/view/5261/Concessoes_Rodoviarias.html. Acesso em: 19 mar. 2017.

ANTT (Agência Nacional de Transportes Terrestres). Gerência de Fiscalização e Controle Operacional de Rodovias. Tráfego de 2015 a 2017, por praça, por sentido, por mês e por categoria, da Concessionária Concebra [dados obtidos por meio do Serviço de Informação ao Cidadão/Lei de Acesso à Informação - Protocolo 50650001067201812]. Brasília: ANTT, 2018.

ARRAIS, T. A; CASTILHO, D; AURÉLIO NETO, O. P. Integração nacional e fragmentação regional: o sentido territorial da BR-153 no centro-norte brasileiro. Geographia, Niterói, v. 18, n. 36, p. 62-85, 2016.

ARROYO, M. M. Fluidez e porosidade do território brasileiro no contexto da integração continental. In: María Laura Silveira. (Ed.). Continente em chamas. Globalização e território na América Latina. Rio de Janeiro: Civilização Brasileira, 2005, p. 209-242.

ARROYO, M. M. Redes e circulação no uso e controle do território. In: Arroyo, Mónica; Cruz, Rita. (Orgs.). Território e Circulação. A dinâmica contraditória da globalização. 1 ed. São Paulo: Annablume, 2015, p. 37-50.

BITTENCOURT, F. M. R. Investimento público federal em infraestrutura de transportes em regime de concessão - subsídios para o desenho de políticas. Textos para discussão, no 60 . Brasília: Centro de Estudos da Consultoria do Senado Federal, 2009.

BRASIL. BNDES aprova empréstimo-ponte de R\$1 bilhão para rodovias. Portal Brasil. 24 jun. 2014. Disponível em: http://www.brasil.gov.br/economia-e-emprego/2014/06/bndes-aprova-emprestimo-ponte-de-r-1-bilhao-para-rodovias. Acesso em: 16 fev. 2017.

BRASIL. Edital de Concessão No004/2013 (Anexo 2). Programa Exploração da Rodovia. BR-060, BR-153, BR-262-DF/GO/MG: trecho de 1.176,50 km das rodovias BR-060, BR-153 e BR-262. Brasília: ANTT, 2013b. 
BRASIL. Edital de Concessão No004/2013 (Parte VII). Contrato de concessão. Rodovia Federal: BR-060, BR-153, BR-262-DF/GO/MG: trecho de 1.176,50 km das rodovias BR-060, BR-153 e BR-262. Brasília: ANTT, 2013a.

CAMPOS NETO, C. A. S; PAULA, J. M. P; SOUZA, F. H. Rodovias brasileiras: políticas públicas, investimentos, concessões e tarifas de pedágio. In: IPEA, Texto para Discussão No. 1668. Rio de Janeiro: IPEA, 2011.

CASTILHO, D. Modernização territorial e redes técnicas em Goiás. Goiânia: UFG, 2016.

CASTILLO, R. A. Agricultura globalizada e logística nos cerrados brasileiros, in SILVEIRA, Márcio Rogério (org.). Circulação, transportes e logística. São Paulo: Outras Expressões, 2011, p. 331-354.

CNT (Confederação Nacional de Transporte) (2017a). Pesquisa CNT de rodovias 2017: relatório gerencial. 21ª ed. Brasília: CNT; SEST; SENAT, 2017.

CONCEBRA (Concessionária das Rodovias Centrais do Brasil S.A.). Balanço anual 2016. Goiânia: Concebra, 2017.

DNIT (Departamento Nacional de Infraestrutura de Transportes). Plano Nacional de Contagem de Tráfego. Disponível em: http://servicos.dnit.gov.br/dadospnct/ContagemContinua. Acesso em: 10 jul. 2017.

GOIÁS (Estado). Secretaria de Estado de Gestão e Planejamento. PIB dos municípios goianos 2014. Goiânia: IMB, 2016.

HARVEY, D. A produção capitalista do espaço. Tradução Carlos Szlak. São Paulo: Annablume, 2005a.

HARVEY, D. O novo imperialismo. Tradução Adail Sobral e Maria Stela Gonçalves. $2^{a}$ ed. São Paulo: Loyola, 2005b.

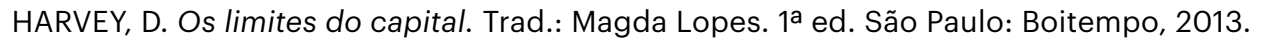

HUERTAS, D. Território e circulação: transporte rodoviário de carga no Brasil. 2013. Tese (Doutorado em Geografia Humana) - Faculdade de Filosofia, Letras e Ciências Humanas, Universidade de São Paulo, São Paulo, 2013.

MARX, K. O capital: crítica da economia política. Livro I (O processo de produção do capital). Tradução Rubens Enderle. $1^{\mathrm{a}}$ ed. São Paulo: Boitempo, 2013.

MARX, K. O capital: crítica da economia política. Livro II (O processo de circulação do capital). Tradução Rubens Enderle. $1^{\mathrm{a}}$ ed. São Paulo: Boitempo, 2014.

NORTH, Douglass. Instituições, mudança institucional e desempenho econômico. Tradução de Alexandre Morales. São Paulo: Três Estrelas, 2018. 255p. 
O POPULAR (Jornal). Manifestantes bloqueiam rodovia contra cobrança de pedágio em Alexânia. O Popular. Goiânia, 30 out. 2015. Disponível em: http://www.opopular.com.br/editorias/cidade/ manifestantes-bloqueiam-rodovia-contra-cobran\%C3\%A7a-de-ped\%C3\%A1gio-em-alex\%C3\%A2nia-1.979334. Acesso em: 23 ago. 2017.

SANTOS, M; SILVEIRA, M. L. O Brasil: território e sociedade no início do século XXI. 12a ed. Rio de Janeiro: Record, 2008. 
